\title{
Exploring Determinants of Unprotected Sexual Behaviours Favouring HIV Transmission among Men who Have Sex with Men in Yogyakarta, Indonesia
}

\author{
Nelsensius K. Fauk ${ }^{1}$, Rik Crutzen ${ }^{2}$, Maria S. Merry ${ }^{3}$, Sukma Putra ${ }^{4}$, Mitra A. Sigilipoe ${ }^{3}$ \& Lillian Mwanri ${ }^{5}$ \\ ${ }^{1}$ Institute of Resource Governance and Social Change, Jl. R. W. Monginsidi II, No. 2, Kel. Kelapa Lima, Kec. \\ Kelapa Lima, Kupang, Nusa Tenggara Timur, Indonesia \\ ${ }^{2}$ Department of Health Promotion, Maastricht University, Maastricht, The Netherlands \\ ${ }^{3}$ Medicine Faculty, Duta Wacana Christian University, Jl. Doktor Wahidin Sudiro Husodo No. 5-25, Yogyakarta, \\ Indonesia \\ ${ }^{4}$ Bina Nusantara University International, Jl. Hang Lekir I No. 6, Senayan, Jakarta, Indonesia \\ ${ }^{5}$ Discipline of Public Health, School of Health Sciences, Flinders University, Adelaide, South Australia, Australia \\ Correspondence: Lillian Mwanri, Discipline of Public Health, School of Health Sciences, Flinders University, \\ GPO Box 2100, Adelaide 5001, South Australia, Australia.
}

Received: April 9, 2017 Accepted: April 27, 2017 Online Published: May 8, 2017

doi:10.5539/gjhs.v9n8p47 URL: https://doi.org/10.5539/gjhs.v9n8p47

\begin{abstract}
A qualitative inquiry using individual interviews explored determinants of unprotected sexual behaviours favouring HIV transmission among Men who Have sex with Men (MSM) in Yogyakarta, Indonesia. The study was conducted in July 2015 with 24 MSM participants recruited using convenience sampling technique. Data were analysed using a qualitative data analysis framework, with the Social Cognitive Theory (SCT) employed as the study conceptual framework. Findings were grouped into a reciprocal triadic relationship involving behavioural, personal (cognitive) and environmental determinants. Behavioural determinants comprised having multiple casual sex partners, engagement in group sex and transactional sex practices. Environmental factors associated with unprotected sexual behaviours included influence of unsafe sex from regular partners and lack of access to HIV-related services. Personal (cognitive) determinants favouring unprotected sexual behaviours identified were lack of knowledge of condom and HIV/AIDS, individuals' expectation of pleasurable sexual intercourse, and low self-efficacy to discuss condom use and HIV status with casual sex partners. As effort to address HIV in MSM in Indonesia is still at its infancy, the findings of the current study are insightful and will inform the development of evidence-based programs in addressing HIV/AIDS problem in MSM populations in Yogyakarta and other similar settings.
\end{abstract}

Keywords: SCT, determinants, unprotected sexual behaviours, HIV transmission, MSM population, Yogyakarta, Indonesia

\section{Introduction}

Over the past ten years, Indonesia has experienced a fast growing number of people living with HIV/AIDS (PLWHA). The number of PLWHA increased from 6,093 in 2005 to 88,719 in 2010, 268,185 in 2015, and 319,103 in 2016 , with corresponding rise in prevalence of HIV/AIDS from $0.05 \%$ in 2011 , to $0.06 \%$ in $2012,0.08 \%$ in $2013,0.10 \%$ in 2014, $0.11 \%$ in 2015, and $0.13 \%$ in 2016 (Kementrian Kesehatan RI, 2017).

Unprotected sexual behaviours have been incriminated as the main contributors to the spread of HIV infection among Indonesian population (Fauk \& Mwanri, 2015; Kementrian Kesehatan RI, 2017; Prasetyo et al., 2014). For example, over the past five years, more than half of the new HIV cases were due to unprotected sexual behaviours (Kementrian Kesehatan RI, 2017). The 2017 national AIDS report and several studies in Indonesia have indicated that Men who have Sex with Men (MSM) populations are highly susceptible to HIV infection due to their frequent engagement in such behaviours (Kementrian Kesehatan RI, 2017; Morineau et al., 2011; Pisani et al., 2004; Prasetyo, et al., 2014). The same report shows that the HIV prevalence among MSM in the country has steadily increased from $2.0 \%$ in 2011 to $3.1 \%$ in $2012,5.0 \%$ in $2013,6.4 \%$ in $2014,7.6 \%$ in 2015 , and $11.8 \%$ in 2016 
(Kementrian Kesehatan RI, 2017). Of an estimated 3 million MSM population in Indonesia, 27,509 people have been diagnosed with HIV infection (Kementrian Kesehatan RI, 2017).

Globally, several studies have reported that unprotected anal intercourses (UAI) are the main contributor to the HIV transmission among MSM. Internet has also been reported as an avenue where strangers meet online, enabling them to engage in UAI offline (Balán, Carballo-Diéguez, Ventuneac, \& Remien, 2009; Berg \& Grimes, 2010; Poon, Wong, Sutdhibhasilp, Ho, \& Wong, 2013). Other factors that have led to MSM engagement in UAI include consumption of excessive alcohol and use of illicit (Balán, et al., 2009; Dillon \&Basu, 2014), social influence among peers, economic pressure (El-Sayed, Darwish, El-Geeneidy, \& Mehrez, 1994; Torres et al., 2013), and the lack of knowledge about how HIV is transmitted and prevented (Colby, 2003; El-Sayed, et al., 1994; Fauk \& Mwanri, 2014b; Han, Lauby, Bond, Pollo, \& Rutledge, 2010; Wong, Zhang, Wu, Kong, \& Ling, 2006).

Several studies conducted in the Indonesian context have also highlighted unprotected sexual behaviours with multiple casual sex partners as the main determinant for HIV transmission among MSM (Morineau, et al., 2011; Pisani, et al., 2004; Prasetyo, et al., 2014). However, less is known about determinants of MSM populations' engagement in unprotected sexual behaviours that increase their susceptible to HIV transmission. Understanding why MSM engage in UAI in Indonesia is important in order to inform the development of programs and strategies that will curb the transmission of the HIV scourge among MSM populations in the country.

\section{Methodology}

\subsection{Theoretical Framework}

The conceptualisation of this study was guided by Bandura's Social Cognitive Theory (SCT). The SCT provides explanation on how factors including: (i) Behavioural (B), (ii) Personal (cognitive) (P), and (iii) Environmental (E) operate interactively and in triadic reciprocal fashion to enable changes in psychosocial functioning or in human behaviours (Bandura, 1986; Neisser, 1976).

For example, the theory explains that what people believe, think, feel, and perceive (P) influences how they behave (B), and the effects of their behaviour or action (B) can also determine how they believe, think, feel and perceive (P) (Bandura, 1986; Neisser, 1976). Likewise, what people believe and think (P) (e.g.: about condom use or protected sexual behaviour) can influence or be modified by socio-environmental factors (e.g.: influence of peers and regular partners) (E). Besides, environmental factors (E) such as social relationships among peers and regular partners, availability of condoms can influence people's sexual behaviour or sexual practices (B), while the common sexual practices (B) among them can also influence their social relationships (E) (Bandura, 1986).

Reciprocality introduced in this theory does not mean symmetry in the strength of bidirectional influences, nor is the patterning and strength of mutual influences fixed in reciprocal causation (Bandura, 1986). The influence exerted by the three sets of interacting factors varies for different activities, individuals and circumstances (Bandura, 1986). This also implies that some personal (cognitive) and environmental factors exercise more powerful influence on one behaviour than on the other, or are more relevant for one behaviour than for the other, and can influence multiple behaviours.

\subsection{Study Design}

A qualitative inquiry using one-on-one face to face interviews was employed to identify factors associated with unprotected sexual behaviours leading to high susceptibility to HIV infections among MSM in Yogyakarta. The use of qualitative design enabled researchers to explore participants' understandings and interpretations about their behaviours, experiences and social relationship, and how these positioned them in HIV transmission (Allsop, 2013; Heyink \& Tymstra, 1993; Rice \& Ezzy, 2005).

\subsection{Recruitment, Data Collection and Ethical Considerations}

A convenience sampling technique was employed to recruit participants. The criteria for inclusion were: a man who has sex with another man, and a man who was 18 years old or above. A nongovernmental employee coordinating an HIV/AIDS program for MSM population agreed to participate in the study. He also provided a list of names and contact numbers of study's potential participants. The potential participants were contacted by phone and informed of the current study which would be conducted in an interview format at their convenient time and place if they agreed.

Three interviewers (NKF, MSM, MAS) conducted the interviews with the participants. They are knowledgeable about the topic and experienced qualitative researchers. Guided by the SCT the interviews aimed to identify behavioural, personal (cognitive) and environmental determinants that contributed to unprotected sexual behaviour among the participants. Interviews were conducted with participants at a mutually agreed time and place. 
Each interview was audio recorded and took between 40 and 90 minutes. Each participant was provided with light snack and IDR 75,000 (equals to US\$ 6) to reimburse for their time at the interview day. All the interviews were conducted in Bahasa, Indonesian national language. Prior to the commencement of interviews, participants were informed of their rights for participation including the choice to discontinue with interviews with no consequences. The research maintained ethical conduct of research including preserving confidentiality, obtaining written informed consent and voluntarism. Each participant signed and returned a written informed consent at the interview day. This study was approved by Medicine Research Ethics Committee, Duta Wacana Christian University, Yogyakarta, Indonesia (Ref. No.: 002-B/C.10/FK/UKDW/VI/2015).

\subsection{Data Analysis}

The recorded audio data were transcribed into coding sheets and translated into English by three authors (NKF, MSM, MAS). They are fluent in Bahasa and English. Data crossed checks for accuracy and clarity among the three authors took place during the transcription and translation process. The transcripts were read repeatedly to identify and analyse determinants of unprotected sexual behaviours among the participants. Data analysis involved five steps suggested in the qualitative data Analysis Framework including data: (i) familiarisation, (ii) thematic identification, (iii) indexation, (iv) charting, and (v) mapping and interpretation (Ritchie \& Spencer, 1994). Initial coding and analysis manually performed by one author (NKF) were assessed, reanalysed if necessary and critically revised for intellectual content by other authors (RC, LM, SP). The analysis framework is a valid data process and provides a systematic approach to data management and enhances rigour, transparency, consistency and structure of the data (Ritchie \& Spencer, 1994; Srivastava \& Thomson, 2009). Recurring themes identified from the data were given headings and sub-headings in order to minimise the likelihood of losing data (Ritchie \& Spencer, 1994; Srivastava\& Thomson, 2009). Both inductive approach, with categories emerging purely from the data, and deductive approach, with categories derived from prior knowledge, were used to analyse the data (Moretti et al., 2011).

\section{Results}

Of 33 invited MSM, 24 men aged between 21-42 years agreed to participate. They originated from 7 different provinces including Yogyakarta, West Java, West Nusa Tenggara, East Nusa Tenggara, Bali, South Sulawesi and South Kalimantan. Of the 24 participants, fourteen (58\%) had their own businesses, three (12\%) were employees of a nongovernmental organisation (NGO), and the rest were studying at university (29\%). The majority of participants $(67 \%)$ had completed senior high school, one $(4 \%)$ had a bachelor degree and the others were university students (29\%). All participants had been diagnosed with at least one of four sexually transmitted infections (STIs), including HIV, syphilis, gonorrhoea and chlamydia. Five of them were HIV positive.

Guided by Bandura's SCT, several interrelated and reciprocating factors associated with unprotected sexual behaviours were identified and grouped into three main categories including: behavioural, personal (cognitive) and social environmental determinants (Bandura, 1986).

\subsection{Behavioural Determinants}

\subsubsection{Multiple SexPartners and Group Sex Practice}

Having multiple casual sex partners was a common sexual practice found to have a strong influence on participants' involvement in unprotected sexual behaviours that led them to being vulnerable to HIV transmission. All the participants acknowledged having unprotected sexual intercourse with concurrent multiple casual partners whom they had met in bars, cafes and through gay social media:

"I have multiple [casual] sex partners whom I met in bars, cafes and via internet. Mostly I met them through internet: chatted and then made an agreement to meet, and if we clicked [like each other] then had sex. They were short-term partners and just for sex for one or two or three times, so we [he and his sex partner] did not use condoms, we did not even talk about condom use" (R15: 37 years old).

"I did not use condoms when having sex with my [casual] partners because we [his and his sex partner] looked for each other through social media such as gay facebook, and gay websites like Planet Romeo, Jack'd, Grinder, Hornet, mIRC, and met up to have sex. I found it difficult to propose condom use to someone I just met. ....." (R5: 42 years old).

Group sex practice, a sexual intercourse that involves three or more sex partners at the same time was another common practice associated with the participants' engagement in unsafe sex or HIV-risk sexual behaviours. Such a practice was explained by the majority of the interviewees. As they were unplanned they were performed when condoms were unavailable. The preference to enjoy sex without condoms was also indicated to be another reason 
for their engagement in unsafe sex:

"I have been a few times involved in sexual intercourse comprising three people [including him] at once when I was in Sulawesi and here in Jogja [nick name of Yogyakarta]. ..... we did not use condoms because the situation was different ..... we did not plan it, we just got together in my friend's room and it happened" (R4: 26 years old).

"I did it [group sex practice] in a group of 3 to 5 people, but so far it [number of sex partners] is not more than 5 people. ..... We did not use condom because we all liked it [sex without condom use]. We wanted to have fun" (R20: 27 years old).

\subsubsection{Transactional Sex Practices}

Transactional sex was another common practice strongly associated with unprotected sexual behaviours among the participants. Clients' disapprovals of condoms, coupled by the need for cash due to economic pressures were the reasons for not negotiating condom use:

"I engage in transactional sex because I get money from it. But I only do it [sell sex] at the time when I do not have money. So it is not my profession. ..... no condom use because my partners [clients] do not like it and they feel uncomfortable using condom during the intercourse" (R11: 22 years old).

"I am a Kucing [Kucing is a term used for a gay prostitute, it literally means cat]. It is because of economic problem. I always feel like the money I have is not enough to fulfil my needs. That is because when I start getting involved in the gay world, I hang out with friends very often, have fun. ..... No condom use because they [clients] do not want to use. Besides, it feels better without protection [condom]" (R3: 25 years old).

\subsection{Socio-Environmental Determinants}

\subsubsection{The Influence of a Regular Partner}

A regular partner was found to have a strong influence on the sexual behaviours of the participants. Disagreement on condom use between participants and their regular partners was a reason for inconsistent use of condoms, increasing their susceptible to HIV transmission:

"It is not only my decision to whether or not to use condoms but our [he and his regular partner] decision. If my [regular] partner does not want to use condom or if I want to use but he says: using condom makes him feel uncomfortable, then we do not use it" (R17: 28 years old).

“.... It [not using condom] is because of the demand of my [regular] partner. It makes me feel bad and not enjoy the sex if I reject what he wants" (R19: 32 years old).

Unavailability of condoms at home seemed to be another reason for unsafe sexual behaviour between the participants and their regular sexual partners. A few interviewees who lived together with their regular partners commented that condoms were hardly available at home because they and their regular partners did not think of accessing and having condoms always available:

"My [regular] partner and I hardly have condoms available at home, so we often do not think of using condoms once having sex" (R2: 25 years old).

".... neither me nor my steady partner think of storing condoms at home so that we can use them anytime we want ..." (R10: 32 years old).

\subsubsection{Access to Health Services}

Health services for the MSM population seemed to have improved in terms of availability and scope. They could easily access health services at the office of an NGO that specifically provided HIV/AIDS program and services for MSM and at the community health centres or hospitals in Yogyakarta. However, judgemental behaviours, shaming or blaming reactions from doctors in some community health centres in Yogyakarta was indicated to be the barriers for them to accessing HIV or STIs related services including condoms and information. As a consequence, some hardly underwent medical check-ups or VCT in the last few years, increasing their likelihood of contracting and spreading STIs including HIV:

"One of the reasons why I do not use condoms is because I do not want to go and get them at the community health centres and at the office of the NGO, that provide them from free. This is because I once got infected with gonorrhoea, I went to a doctor at a community health centre but I felt uncomfortable because the doctor raised too many embarrassing questions: have you got married? Why don't you get married? Why did you do this [have sex with man]? If you want to do this [have sex] you should do it with a proper partner [a woman]..... I was not able to 
answer these questions" (R9: 27 years old).

"I got a bad experience with a doctor at a community health centre here [Yogyakarta]. I visited her because I got infected with syphilis. She asked me to change my sexual orientation. I went there because I needed treatment for the infection, not for my sexual orientation. It was really uncomfortable and very awkward. Since then I have never accessed health services including condoms in the last two years and been inconsistently using condoms" (R23: 28 years old).

\subsection{Personal (Cognitive) Determinants}

\subsubsection{Lack of Knowledge of HIV Infection and Condom Use}

Lack of knowledge about how HIV is transmitted was one of the reasons associated with HIV-risk sexual behaviours. Several participants interviewed commented that they did not have knowledge and information at all about HIV/AIDS before joining the gay community and activities in Yogyakarta. Moreover, some participants who have been exposed to HIV/AIDS knowledge and information seemed to be still inconsistent in using condoms:

"I did not know anything about HIV/AIDS before moving here and joining gay activities with my [MSM] colleagues. .... I never thought of condoms either" (R1: 22 years old).

"I started learning about HIV since I joined HIV/AIDS program run by some of my [MSM] colleagues. I was very afraid once I knew about the means of HIV transmission because I did not use condom at all. Now, I often use condoms but sometimes I do not use, I think that is fine" (R18: 24 years old).

Lack of knowledge of condom and its benefits and protective functions was also associated with the participants' consistent engagement in unprotected sexual behaviour. Besides, it was also evident that although some participants were aware of the benefits of condom use, they still inconsistently used them:

"Before, I did not use condoms at all because I did not know anything about it. After I attended VCT provided by an NGO here [Yogyakarta] I often use condoms up to now but sometimes I do not use because I just do not have it at the time when having sex" (R12: 22 years old).

"I gain much information about condoms and learn about the protective functions of condoms here. So now I regularly access condoms because condoms are easy to get here. But you know sometimes I just don't want to use [condoms]" (R7: 27 years old).

\subsubsection{Personal Expectation of Sexual Pleasure}

The expected sexual pleasure associated with risky sexual behaviours among the participants seemed to be a contributor to UAI. The sexual discomfort and displeasure experienced when using condoms were mentioned as reasons for inconsistent use of condoms by a few participants:

"I use condom inconsistently. If I want to use then I use but I often do not use it. The sensation is different. It feels better without condom" (R13: 25 years old).

"I don't like if my partners use condoms because as a bottom [receptive] person it feels hot when there is a friction between the latex and anus during the intercourse" (R15: 37 years old).

\subsubsection{Self-Efficacy}

Low self-efficacy to talk about condom use with their short-term or casual sex partners was another supporting factor for the participants' engagement in HIV-risk sexual behaviours. Participants expressed that they feared losing or offending sexual partners with subsequent cancellation of a sexual contact if they talked about using condoms with their casual partners:

"I do not talk about condom use with casual partners because I am afraid of losing my [casual] partner, so I do not use condoms when having sex with them" (R14: 25 years old).

"To be honest I do not use condoms and do not want to talk about condoms because he [casual partner] can feel offended and change his mind or cancel it [sexual intercourse] if he does not like the topic" (R3: 22 years old).

Furthermore, the avoidance of discussion about STIs including HIV status of their casual partners could have also played an important role in the participants' engagement in UAI. Avoidance of discussing HIV status with partners seemed to arise from the lack of courage to ask whether or not a casual sexual partner was infected with HIV or other STIs, and was due to the belief that such a discussion was impolite and hurtful to the partner:

"I am aware that it is important to know whether my [casual] partner is clean [infected] or not so that I can protect myself but I am not brave enough to ask every time I meet someone [casual sex partner]. I do not even know where to start. That is why I inconsistently use condoms when having sex with short-term [casual] partners" 
(R8: 23 years old).

"I do not ask about that [HIV and STIs status of casual partners] at all. It would hurt me if my [casual] partner asks me that, so I guess he would feel the same if I raise such talk. He might feel that I am suspicious about his HIV status, but to be honest if I know that my partner is infected with STIs or HIV I would definitely use condoms" (R16: 23 years old).

\section{Discussion}

The World Health Organisation has addressed MSM population as one of the most susceptible groups to the HIV transmission (WHO, 2015). Individuals' engagement in risky sexual behaviours or UAI has been incriminated as the main contributor to the spread of the epidemic among them (Mumtaz, Hilmi, McFarland, Kaplan, \& Akala, 2011; Mustanski, Newcomb, Du-Bois, Garcia, \& Grov, 2011). Consistent with the results of several previous studies (El-Sayed, IA, \& El-Gueniedy, 2008; Mimiaga et al., 2009; Morineau, et al., 2011; Poon, et al., 2013), the current study confirms that having multiple casual sex partners was one of the behavioural determinants strongly associated with HIV-risk sexual practice among the participants. Likewise, enjoyment associated with group sex practices and their preference to experience sexual sensation without condoms, coupled with the unavailability of condoms at time when such practices happened, were enablers to MSM engagement in UAI. Findings of the current study conform to previous studies (Egypt Ministry of Health and Population National AIDS Program, 2006; El-Sayed, et al., 1994; Elrashied, 2006; Mahfoud, Afifi, Ramia, El-Khoury, \& Kassak, 2010), including, that participants' engagement in transactional sex practices as male sex workers put them in a weak position for safe sex negotiation. These findings also support results of previous studies (Balán, et al., 2009; Berg \& Grimes, 2010; Elford, Bolding, \& Sherr, 2001; Mettey, Crosby, DiClemente, \& Holtgrave, 2003; Poon, et al., 2013), that inform the use of internet to meet online sex partners for offline sex and transactional sex as the common practices that contributed to unprotected sexual behaviours among MSM populations. On the contrary, other practices including the use of drugs and excessive alcohol consumption, which have been widely reported as associated with UAI among MSM (Clutterbuck, Gorman, McMillan, Lewis, \& Macintyre, 2001; Drumright et al., 2006; Hirshfield, Remien, Humberstone, Walavalkar, \&Chiasson, 2004; Parsons \&Halkitis, 2002), were not found to be the case in the current study.

Findings of the current study support previous studies on the environmental determinants of unprotected sexual behaviours among MSM populations. For instance, the influence of regular sex partners, as previously reported (Koblin et al., 2003; McLean et al., 1994; Parsons \& Bimbi, 2007; Semple, Patterson, \& Grant, 2003) on unsafe sexual behaviours of MSM was confirmed in the results of this study. Similarly, judgemental behaviours or shaming and blaming reactions of medical doctors towards MSM's sexual orientation were a hindrance for MSM individuals to accessing health services. Such stigmatizing attitudes by medical practitioners further reduced MSM's willingness to access services, hence promoting the spread of HIV infection among them. Other studies in Indonesia and elsewhere have identified judgemental behaviours to preclude transgender population and motorcycle taxi drivers (tukang ojek) from accessing HIV/AIDS-related information, predisposing them to continuous engagement in HIV risky sexual behaviours (De-Santis, 2009; Fauk \& Mwanri, 2014a).

Furthermore, this study as well as previous studies (Colby, 2003; El-Sayed, et al., 1994; Elrashied, 2006) identified contributors to MSM's engagement in unprotected sex as following: (i) the lack of knowledge of HIV transmission and prevention, and (ii) lack of knowledge of condom use as protective determinants to HIV infections. These findings support the SCT and are in the personal (cognitive) factors category, where knowledge, efficacy and outcome expectations tend to influence behaviours (Bandura, 1986; Neisser, 1976). Some participants in current study findings had knowledge about protective functions of condoms, but did not use condoms consistently. This is not surprising as similar findings have been noted in previous studies (Malebranche, Fields, Bryant, \& Harper, 2009; Wheeler, 2006; Williams, Wyatt, Resell, Peterson, \& Asuan-O'Brien, 2004), where participants continued to engage in unprotected sexual behaviours after being exposed to such knowledge. Furthermore, similar to previous reporting (McLean, et al., 1994), the findings of the current study support the notion that individuals' expectations for sexual pleasure or perceptions that condom use interfere with sexual satisfaction were associated with unprotected sexual behaviours among MSM. Low self-efficacy including avoiding to discuss condom use and STIs issues with casual sex partners due to fear of losing and/or offending them, was identified as a determinant associated with unprotected sexual behaviours among MSM in the current study.

\subsection{Limitations and Strengths}

There are some limitations that need to be mentioned with regard to the current study. Because the majority of participants were living in the city centre of Yogyakarta, which has differing opportunities from other settings in Indonesia and elsewhere, it is not possible to generalise the findings of the study to all MSM populations. The 
participants were recruited based on the initial participant who had been involved in various HIV/AIDS programs and had access to the already available HIV/AIDS-related services and information. Compared to other MSM from other settings in Indonesia, the current study's participants' involvement in such programs may have increased their perceptions and knowledge about HIV risks and the means of HIV transmission and prevention. This might have resulted in under-sampling of MSM from other parts of Yogyakarta who are hardly exposed to HIV/AIDS programs, services and information. Such under-sampling might result in an incomplete or biased overview of factors associated with HIV-risk sexual behaviours in the current study. This study did not make comparison, for example, identifying and interviewing a group of MSM that would have regular engagement in safer sex practices to distinguish which factors and behaviours were associated with risky behaviours compared to factors simply associated with MSM. As such, it is likely that these results might not be transferable to broader populations where some of the high risk behaviours are unknown. These are important issues that could be explored in further studies.

Despite these limitations, to our knowledge, the current study represents the first qualitative investigation of the determinants of unprotected or unsafe sexual behaviours among MSM in Indonesia. A qualitative approach was used in this study because it provides in-depth and highly contextualised information and insights into pertinent issues including those associated with HIV-risk sexual behaviours among the MSM in Yogyakarta.

\section{Conclusions}

This study reports several behavioural, environmental and personal (cognitive) determinants associated with MSM's engagement in unprotected sexual behaviours that may increase their susceptibility to HIV transmission. They include having multiple casual sex partners, engagement in transactional sex and group sex practices, the use of internet to find online partner for offline sex, the influence of regular sex partner, lack of access to HIV-related services, lack of knowledge of condoms and HIV/AIDS, individuals' expectation of pleasurable sexual intercourse, and low self-efficacy to propose discussion on condom use and HIV status with casual sex partners. The results of this study can be used to inform government institutions, NGOs, policy makers and program planners to support and develop evidence-based programs in addressing HIV/AIDS problem among MSM in Yogyakarta and Indonesia as a whole. Further studies with a larger number of MSM participants from varying backgrounds such as ethnicity and geographical area, are recommended to increase an understanding about what could be done by the authorities to reduce the susceptibility to HIV in MSM populations.

\section{Authors' Contributions}

NKF was involved in the data collection, data analysis and interpretation, and in drafting the paper, revising it critically for important intellectual content. RC was involved in data analysis and interpretation, and in drafting the paper, revising it critically for important intellectual content. MSM and MAS were involved in the data collection, transcription and interpretation. SK was involved in revising the paper for important intellectual content. LM was involved in data analysis and interpretation and in revising it critically for important intellectual content. No writing assistance was provided in the production of this paper.

\section{Competing Interests Statement}

No potential conflict of interest was reported by the authors.

\section{References}

Allsop, J. (2013). Competing paradigms and health research: design and process. In M. Saks \& J. Allsop (Eds.), Researching Health, Qualitative, Quantitative and Mixed Methods (pp. 18-41). London: Sage.

Balán, I. C., Carballo-Diéguez, A., Ventuneac, A., \&Remien, R. H. (2009).Intentional condomless anal intercourse among Latino MSM who meet sexual partners on the internet.AIDS EducPrev, 21(1), 14-24.https://doi.org/10.1521/aeap.2009.21.1.14

Bandura, A. (1986). Social Foundations of Thought and Action: A Social Cognitive Theory. New Jersey: Stanford Univeristy.

Berg, R. C., \& Grimes, R. (2010). Do traditional risk factors predict whether men who have sex with men engage in unprotected anal intercourse? The need for locally based research to guide interventions.Health, 15(5), 517-531. https://doi.org/10.1177/1363459310384494

Clutterbuck, D. J., Gorman, D., McMillan, A., Lewis, R., \& Macintyre, C. C. (2001). Substance use and unsafe sex amongst homosexual men in Edinburgh.AIDS Care, 13, 527-535. https://doi.org/10.1080/09540120120058058

Colby, D. (2003). HIV Knowledge and Risk Factors Among Men Who Have Sex with Men in Ho Chi Minh City, 
Vietnam. J Acquir Immune Def Syndr, 32, 80-85. https://doi.org/10.1097/00126334-200301010-00012

De-Santis, J. P. (2009). HIV infection risk factors among male-to-female transgender: A review of the literature. $J$ Assoc Nurses AIDS Care, 20, 362-372. http://dx.doi.org/10.1016/j.jana.2009.06.005

Dillon, J. P., \& Basu, A. (2014). HIV/AIDS and Minority Men Who Have Sex with Men: A Meta-Ethnographic Synthesis of Qualitative Research. Health Commun, 29(2), 182-192. http://dx.doi.org/10.1080/10410236.2012.732911

Drumright, L. N., Little, S. J., Strathdee, S. A., Slymen, D. J., Araneta, M. R., \& Malcarne, V. L. (2006). Unprotected anal intercourse and substance use among men who have sex with men with recent HIV infection.J Acquir Immune DeficSyndr, 43, 344-350. https://doi.org/10.1097/01.qai.0000230530.02212.86

Egypt Ministry of Health and Population National AIDS Program. (2006). HIV/AIDS biological and behavioral surveillance survey, Round I, Summary report Egypt 2006. Cairo, Egypt: Ministry of Health. Retrieved from https://www.fhi360.org/sites/default/files/media/documents/EgyptBioBSSsummaryreport2006.pdf

El-Sayed, N., Darwish, A., El-Geeneidy, M., \& Mehrez, M. (1994). Knowledge, Attitude, and Practice of Homosexuals Regarding HIV in Egypt.National AIDS Program. Cairo, Egypt: Ministry of Health and Population.

El-Sayed, N., IA, I. A. K., \& El-Gueniedy, M. (2008). Risk behaviours for HIV/AIDS infection among men who have sex with men in Cairo, Egypt. East Mediterr Health J, 14, 905-915. Retrieved from https://www.ncbi.nlm.nih.gov/pubmed/19166174

Elford, J., Bolding, G., \& Sherr, L. (2001). Seeking sex on the Internet and sexual risk behaviour among gay men using London gyms.AIDS, 15, 1409-1415.https://doi.org/10.1097/00002030-200107270-00010

Elrashied, S. (2006). Prevalence, knowledge and related risky sexual behaviours of HIV/AIDS among receptive men who have sex with men (MSM) in Khartoum State, Sudan, 2005. Paper presented at the AIDS 2006-XVI International AIDS Conference, Toronto, Canada. Retrieved from https://books.google.co.id/books?id=WepARRFDEAwC\&pg=PA327\&lpg=PA327\&dq=Elrashied,+S\&sourc e=bl\&ots=vvn-lHk8I6\&sig=s4n_S_nIOqnEds2hdJmWP9-T8xA\&hl=en\&sa=X\&ved=0ahUKEwjo9onf5JT TAhVIRY8KHQgaDnkQ6AEINzAF\# $\mathrm{v}=$ onepage $\& \mathrm{q}=$ Elrashied $\% 2 \mathrm{C} \% 20 \mathrm{~S} \& \mathrm{f}=$ false

Fauk, N. K., \& Mwanri, L. (2014a). Economic and environmental determinants of Ojek's susceptibility to HIV infection. Int $J$ Appl Pharm Sci Bio Med Sci, 3(1), 291-300. Retrieved from https://www.researchgate.net/publication/263031488_Economic_and_Environmental_Determinants_of_Oje k's_Susceptibility_to_HIV_Infections

Fauk, N. K., \& Mwanri, L. (2014b). Individual and Contextual Risk Factors of the HIV Pandemic in Young Adults.A case of school, college and university students in China.Int J Res SocSci, 4(3), 578-597. Retrieved from http://citeweb.info/20141496104

Fauk, N. K., \& Mwanri, L. (2015). Inequalities in addressing the HIV epidemi: The story of the Indonesia Ojek community. Int J Hum Rights Healthcare, 8(3), 144-159. https://doi.org/10.1108/IJHRH-10-2014-0028

Han, C. S., Lauby, J., Bond, L., Pollo, A. B., \& Rutledge, S. E. (2010). Magic Johnson doesn't worry about how to pay for medicine: Experiences of Black men who have sex with men living with HIV. Cult Health Sex, 12, 387-399. https://doi.org/10.1080/13691050903549030

Heyink, J. W., \& Tymstra, T. J. (1993). The Function of Qualitative Research. Soc Indic Res, 29(3), 291-305. https://doi.org/10.1007/BF01079517

Hirshfield, S., Remien, R. H., Humberstone, M., Walavalkar, I., \&Chiasson, M. A. (2004). Substance use and high-risk sex among men who have sex with men: A national online study in the USA. AIDS Care, 16, 1036-1047. https://doi.org/10.1080/09540120412331292525

Kementrian Kesehatan RI. (2017). Laporan Situasi Perkembangan HIV/AIDS di Indonesia Tahun 2016. Jakarta, Indonesia: KementrianKesehatan RI. Retrieved from http://www.aidsindonesia.or.id/

Koblin, B. A., Chesney, M. A., Husnik, M. J., Bozeman, S., Celum, C., \& Buchbinder, S. (2003). High-risk behaviors among men who have sex with men in 6 US cities: Baseline data from the EXPLORE Study. Am J Public Health, 93, 926-932. https://doi.org/10.2105/AJPH.93.6.926

Mahfoud, Z., Afifi, R., Ramia, S., El-Khoury, D., \& Kassak, K. (2010). HIV/AIDS among female sex workers, injecting drug users and men who have sex with men in Lebanon: results of the first biobehavioral surveys. 
AIDS, 24(Suppl 2), S45-54. https://doi.org/10.1097/01.aids.0000386733.02425.98

Malebranche, D. J., Fields, E. L., Bryant, L. O., \& Harper, S. R. (2009). Masculine socialization and sexual risk behaviors among Black men who have sex with men.Men Masc, 12, 90-112. Retrived from http://journals.sagepub.com/doi/abs/10.1177/1097184X07309504?journalCode=jmma

McLean, J., Boulton, M., Brookes, M., Lakhani, D., Fitzpatrick, R., \& Dawson, J. (1994). Regular partners and risky behavior: Why do gay men have unprotected intercourse? AIDS Care, 6, 331-341. https://doi.org/10.1080/09540129408258645

Mettey, A., Crosby, R., DiClemente, R. J., \& Holtgrave, D. R. (2003). Associations between Internet sex seeking and STI associated risk behaviors among men who have sex with men. Sex Transm Infect, 79, 466-468. https://doi.org/10.1136/sti.79.6.466

Mimiaga, M. J., Noonan, E., Donnell, D., Safren, S. A., Koenen, K. C., \& Gortmaker, S. (2009). Childhood sexual abuse is highly associated with HIV risk-taking behavior and infection among MSM in the EXPLORE Study. J Acquir Immune Defic Syndr, 51, 340-348. https://doi.org/10.1097/QAI.0b013e3181a24b38

Moretti, F., Bensing, J., Deledda, G., Mazzi, M., Rimondini, M., Zimmermann, C., \& Fletcher, I. (2011). A standardized approach to qualitative content analysis of focus group discussions from different countries. Patient Educ Couns, 82(3), 420-428. https://doi.org/10.1016/j.pec.2011.01.005

Morineau, G., Nugrahini, N., Nurhayati, R. P., Girault, P., Mustikawati, E. D., \& Magnani, R. (2011). Sexual Risk Taking, STI and HIV Prevalence among Men Who Have Sex with Men in Six Indonesian Cities. AIDS Behav, 15, 1033-1044. https://doi.org/10.1007/s10461-009-9590-6

Mumtaz, G., Hilmi, N., McFarland, W., Kaplan, R. L., \& Akala, F. A. (2011). Are HIV Epidemics among Men Who Have Sex with Men Emerging in the Middle East and North Africa?: A Systematic Review and Data Synthesis. PLoS Med, 8(8), 1-15. https://doi.org/10.1371/journal.pmed.1000444

Mustanski, S. B., Newcomb, E. M., Du-Bois, N. S., Garcia, C. S., \&Grov, C. (2011). HIV in Young Men Who Have Sex with Men: A Review of Epidemiology, Risk and Protective Factors, and Interventions. J Sex Res, 48(2-3), 218-253. https://doi.org/10.1080/00224499.2011.558645

Neisser, U. (1976).Cognition and reality: Principles and implications of cognitive psychology. San Francisco: Freeman.

Parsons, J. T., \& Bimbi, D. S. (2007). Intentional unprotected anal intercourse among sex who have sex with men: Barebacking-from behavior to identity. AIDS Behav, 11, 277-287. https://doi.org/10.1007/s10461-006-9135-1

Parsons, J. T., \& Halkitis, P. N. (2002). Sexual and drug-using practices of HIV-positive men who frequent public and commercial sex environments. AIDS Care, 14, 815-826. https://doi.org/10.1080/0954012021000031886

Pisani, E., Girault, P., Gultom, M., Sukartini, N., Mustiwatik, E. D., Jazan, J., \& Donegan, S. (2004). HIV, syphilis infection, and sexual practices among transgenders, male sex workers, and other men who have sex with men in Jakarta, Indonesia. Sex Transm Infect, 80, 536-540. https://doi.org/10.1136/sti.2003.007500

Poon, M. K., Wong, J. P., Sutdhibhasilp, N., Ho, P. T., \& Wong, B. (2013). Sexual practices and sex-seeking behaviours among East and Southeast Asian men who have sex with men in Toronto: Implications for HIV prevention. Can J Hum Sex, 22(2), 77-85. https://doi.org/10.3138/cjhs.2013.2200

Prasetyo, A. A., Ariapramuda, E. R., Al-Kindi, E., Dirgahayu, P., Sari, Y., Dharmawan, R., . . Kageyama, S. (2014). Men having sex with men in surakarta, indonesia: demographics, behavioral characteristics and prevalence of blood borne pathogens. Southeast Asian J Trop Med Public Health, 45(5), 1032-1047. Retrieved from https://www.ncbi.nlm.nih.gov/pubmed/25417504

Rice, P. L., \& Ezzy, D. (2005). Qualitative Research Method: A Health Focus. Melbourne: Oxford University Press.

Ritchie, J., \& Spencer, L. (1994). Qualitative data analysis for applied policy research. In A. Bryman\& R. G. Burgess (Eds.), Analyzing Qualitative Data (pp. 173-194). London: Routledge. https://doi.org/10.4324/9780203413081_chapter_9

Semple, S. J., Patterson, T. L., \& Grant, I. (2003). HIV-positive gay and bisexual men: Predictors of unsafe sex. AIDS Care, 15, 3-15. https://doi.org/10.1080/713990434

Srivastava, A., \& Thomson, S. B. (2009). Framework analysis: A qualitative methodology for applied policy 


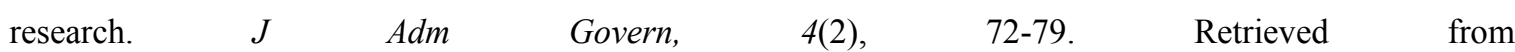
https:/www.researchgate.net/publication/267678963_Framework_Analysis_A_Qualitative_Methodology_f or_Applied_Policy_Research

Torres, L. H., Delonga, K., Lee, S., Gladstone, A. K., Barrad, A., Huckaby, S., . . . Gore-Felton, C. (2013). Sociocontextual Factors: Moving Beyond Individual Determinants of Sexual Risk BehaviorAmong Gay and Bisexual Adolescent Males. J LGBT Youth, 10(3), 173-185. https://doi.org/10.1080/19361653.2013.799000

Wheeler, D. P. (2006). Exploring HIV prevention needs for nongayidentified Black and African American men who have sex with men: A qualitative exploration. Sex Transm Dis, 33(7), S11-S16. https://doi.org/10.1097/01.olq.0000216021.76170.e1

WHO. (2015). HIV and Young Men Who Have Sex with Men. Geneva, Switzerland: World Health Organization. Retrieved from http://www.who.int/hiv/pub/toolkits/hiv-young-msm/en/

Williams, J. K., Wyatt, G. E., Resell, J., Peterson, J., \& Asuan-O’Brien, A. (2004). Psychosocial issues among gayand non-gay-identifying HIVseropositive African American and Latino MSM. Cultur Divers Ethnic Minor Psychol, 10, 268-286. https://doi.org/10.1037/1099-9809.10.3.268

Wong, W. C., Zhang, J., Wu, S. C., Kong, T. S. K., \& Ling, D. C. Y. (2006). The HIV-related risks among men having sex with men in ruralYunnan, China: a qualitative study. Sex Transm Infect, 82, 127-130. https://doi.org/10.1136/sti.2005.016790

\section{Copyrights}

Copyright for this article is retained by the author(s), with first publication rights granted to the journal.

This is an open-access article distributed under the terms and conditions of the Creative Commons Attribution license (http://creativecommons.org/licenses/by/4.0/). 